\title{
EDITORIAL
}

\section{Aging from a Global Perspective, Fall Narratives and Much More ...}

DOI:http://dx.doi.org/10.5770/cgj.16.84

Hello! As you read this letter, our annual meeting of the Canadian Geriatrics Society has just wound down. It was a fantastic conference, and all the abstracts from the excellent research presented in Toronto are included in this issue of the Journal.

I am pleased to present the spring issue of the Canadian Geriatrics Journal. In this issue we have a wide variety of topics including an examination of the use of fall narratives in an older adult falls clinic (C. Wong, et al.) and a review of the issues surrounding the aging population from a global perspective (H. Bergman, et al.). We also have included a study by S. Rej, et al. examining the impact of antidepressants on the risk of lithium-induced hypernatremia, and a descriptive study by L. Kumeliauskas, et al. of the characteristics of patients admitted to hospital with "failure to thrive." Dr. Z. Ismail has also conducted a survey of the types of cognitive screening instruments used by Canadian psychiatrists during their assessments.
Have a great Spring! Dr. Kenneth M. Madden Editor-in-Chief Canadian Geriatrics Journal 